\title{
LEARNING DISABILITIES: EDUCATIONAL AND ASSESSMENT CONSIDERATIONS
}

\author{
William M. Cruickshank \\ School of Public Health, The University of Michigan, Ann Arbor, MI 48109, U.S.A.
}

\begin{abstract}
Al though not every learning disabled child is hyperactive, nor is every hyperactive child necessarily learning disabled, a significant percentage of learning disabled children display the behavioral characteristics of either sensory or motor hyperactivity. Having concomitant learning and management problems, such children provide teachers and school administrators with a most intricate and bewildering problem. Although no one can question the sincere dedication of most teachers, one finds from talking with them that they often find it difficult to deal with a child when he or she fails to respond to instruction or when the child continually disrupts classmates. Such unfortunate interactions between the teacher and the child, and between the child and other children, present a challenge to the teacher. This educational and behavioral stalemate will be analyzed through examining the issue of hyperactivity, considering the essential needs of hyperactive children, and indicating the appropriate educational setting and curriculum considerations that must be kept in mind for hyperactive children. Assessment and management recommendations will be made throughout the analyses.
\end{abstract}

In my opinion learning disability consists of two major aspects, both of which are intimately interrelated and organically based. Admittedly, the concept of hyperactivity as organically based is somewhat theoretical at our present state of knowledge. Although education has done little in this area, the brain-injured child as a clinical entity has been acknowledged by medicine, psychology and to a lesser extent by education for some three to four decades. It should be mentioned that the term "brain-injured" does not refer here to the grossly involved cerebral palsy child, although many of these children also come within its scope. Nor does it refer to children with epilepsy, although these children too have neurological abnormalities and many of them fall within this group. The term refers to children who have suffered prenatal, perinatal, or postnatal brain-injury and consequently display a particular syndrome of psychological characteristics. As a result they often fail to respond in particular learning situations. Two aspects of the problem will be examined in some detail; then assesment problems aimed at illustrating the perceptual processing problems so typical of these children will be considered.

Distractibility is one of the chief characteristics of sensory hyperactivity. Because of an assumed lack of cortical control, the child is unable to attend to a stimulus or group of stimuli for a length of time sufficient 
enough to allow him to respond appropriately. The normal child with an intact central nervous system can usually ignore irrelevant stimuli and concentrate on the task at hand. Hyperactive children, however, are "compelled" to react positively to extraneous stimuli in their environment. The problem can involve a11 of the sensory channels: visual, auditory, tactual, thermal, taste and smell. The hyperactive child, forced to attend to the multitude of environmental stimuli inessential to the task at hand, is unable to separate the figure from the ground, for example. Random colors, noises and movements may, at any time, distract him and cause him to respond.

Sensory hyperactivity is exhibited in a number of ways. Because of constant forced responsiveness, the hyperactive child characteristically has an exceedingly short attention span. The writer has often seen children with attention spans of much less than one minute. When a child has a one- or twominute attention span under the best of conditions, what degree of success can be expected when the lesson plan calls for a twenty-minute reading period? The last eighteen minutes becomes a disciplinary hassle instead of an intructional experience.

Typical reading material compounds the problem. For example, a page may contain 150 words, each containing about five letters. Thus a total of 750 letters may appear on a single page. With a space between each letter and word, there are another 750 spaces. Because each letter forms an angle both with itself and with other letters there is an infinite number of possible angles and relationships of a visual nature. On this page there may also be a drawing or photograph with various lines and colors. The point I am making is that there may be literally hundreds of stimuli before the child on a single page of a reading book. In such a highly stimulating situation, which provides no problem for the normal child, a hyperactive child is asked to "begin reading on the first word of the first line of the third paragraph." What is important to consider here is that the first word is the figure. If he is distracted by the various sources of background stimuli on the page, he will be unable to attend to the appropriate word, the figure. Thus he may not be even capable of finding the appropriate place on the page. The terminology used by psychologists to describe such a phenomenon is "figure-background pathology." At the root of this figure-ground problem, however, is the inability of the child to refrain from reacting to inessential stimuli. Thus the child with figurebackground problems may know the meaning of the words on the printed page before him, but still be unable to "read."

The same child may be asked to assemble a block design. There may be about ten multi-colored blocks - ten stimuli multiplied by the number of colors. Because of the bombardment of the stimuli the child may not be able to conceptualize the design he is asked to copy. Such an inability is called dissociation, but this psychological phenomenon can be thought of as due to sensory hyperactivity. The numerous learning taks requiring the conceptualization of things as a whole makes dissociation a problem of great magnitude.

Motor hyperactivity may be accurately termed motor disinhibition, which refers to the inability of an individual to refrain from making a motor response to a stimulus. These are children who are constantly pulling, twisting, bending (i.e., manipulating everything they can reach with their hands). These are the children who pull the pigtails of the girl in the seat in front of them, who are always pushing or pulling others when standing in a line. (Behavior similar to this is evident in the normal development of the preadolescent, thus careful discrimination must be made between what is normal and what is pathological.) These hyperactive children seem to "fall apart" in social situations requiring composure. Wide-open areas and the uncontrolled space of the playground, the 
school hallways or the playground provide innumerable opportunities for the child to overreact to stimuli and thus makes appropriate adjustment difficult. Physical tensions resulting from these experiences and situations elicit, in turn, motor reactions from the hyperactive child. This combination of sensory distractibility and motor disinhibition constitutes a psychological barrier to learning that leaves the teacher and the child's parents with perplexing problems.

\section{DEFINITION AND ASSESSMENT}

With the brief background provided above one can derive a working definition of such learning disabled children and subsequently develop a pattern of assessment appropriate to the educational needs of the child.

Learning disabilities are problems in the acquisition of developmental skills, academic achievement, social adjustment, and secondarily emotional growth and development, which are the result of perceptual and linguistic processing deficits. Further defined, learning disabilities ... may be of any etiological order, ... of any level of intellectual function ... (They) are the result of perceptual processing deficits which, in turn ... are or may be the result of a (diagnosed or inferred) neurophysiological dysfunction occurring at prenatal, perinatal, or (in the case of linguistic dysfunction) at the postanatal periods of development.

(Cruickshank, 1981)

The key issue in the preceeding definitional statement, from a diagnostic and assessment point of view, is that of "perceptual processing deficits." These may be of diverse form and variety, but often in their disparate aspects they may be seen to be closely related to the issue of attention disturbances and forced responsiveness to stimuli. There are numerous processing deficits that must be evaluated prior to conceptualizing an educational program for these children. A selected group of these issues, some overlapping with one another, have been chosen for description in this paper. (The greater part of the text relating to the following five issues is taken from Cruickshank, 1981.)

1. Discrimination. Children with learning disabilities frequently show an inadequte ability in the recognition of "fine differences between auditory and visual" and tactual "discriminating features underlying the sounds used in speech and the orthographic forms used in reading" (Wepman et al., 1975, p. 309). Golick speaks of this same characteristic under the heading of inadequate "visual efficiency" (1970, p. 8). She emphasizes an important dimension that others have often overlooked, namely, that "with some, the problems seem to be poor perception of the three-dimensional world, yet two-dimensional vision - for written material, pictures - is intact." Studies with cerebral palsy children have also indicated visual efficiency differences between two- and threedimensional material (Cruickshank, Bice, Wallen, \& Lynch, 1965).

The Wepman Committee stressed discriminatory malfunction in terms of auditory and visual modalities. To these may be added tactual (haptic) discrimination in some children. Al though the visual and auditory modalities are undoubtedly the most significant in terms of learning, some research of a minimal nature exists to indicate that the processing deficits here under consideration are probably to be observed in all of the sensory modalities. This fact, although not firmly authenticated, should be kept in mind as subsequent characteristics of perceptual processing deficits are briefly discussed. 
To assess discriminative abilities, multidisciplinary personnel may need to be utilized. Auditory discrimination is essential to understand, and here differences between frequencies and intensity are important to evaluate. Auditory perception and its evaluation, going beyond the usual audiometric testing limits and requiring personnel versed in the matter of perceptual measurement, is essential to understand the child, and should include the issues both of gross and fine auditory discrimination.

Commercial tests are rarely available to assist the psychologist in the assessment of learning disabled children and youth. Good qualitative evaluation is the rule. No tests of a comercial nature exist, for example, in the assessment of a child's ability to discriminate between color shades or tones, or between pressures on the palm of the hand or foot. Yet these skills, based as is all learning on the efficiency of the neurological system, are essential to the various aspects of adjustment as mentioned above in the definition. Psychologists generally, at least in the United States, receive too little training or experience in issues of qualitative assessment.

2. Memory. Children with learning disabilities often show an inadequte ability in "retaining and recalling those discriminted sounds and forms in both short- and long-term memory" (Wepman et al., 1975). In its report to the House of Representatives, the Australian Select Committee on Specific Learning Disabilities (1976, p. 129) stressed "poor short-term rote memory" as a characteristic of "perceptual difficulties". Although failure to remember is an oftheard complaint of teachers and parents, it may not be a discrete processing deficit, but rather the result of other factors, which will be mentioned later. However, the inability to recall constitutes a tremendous hazard to successful achievement, is a characteristic noted by most authors, and indeed was stressed in what was perhaps the first published description of these children under the heading of a "Composite of a Child" (Cruickshank, Bentzen, Ratzberg, \& Tannhauser, 1961 , p. 55).

The capacity of the learning disabled child to recall is basic to many learned skills both in and out of the school situation. For example, the ability to recall is crucial in the multiplication facts, directions within the community, and in many other aspects of learning. Here the memory for digits contained in numerous quantitative intelligence tests (i.e., the Wecheler tests, the Woodcock-Johnson tests, and others) can be of assistance. Memory for auditory patterns can be qualitatively evaluated by tapping out patterns for the child on the examiner's knee or on a small drum. The child repeats what he has heard. The examiner can blindfold the child and tap out patterns on the palm of the child's hand to ascertain haptic perception and memory. Memory is more than visual memory as is involved in flash cards or pictures. Total sensory systems are involved in a complete concept of memory and its relationship to learning.

3. Sequencing. Closely related to memory is another factor that must be evaluated by psycho-educational diagnosticians. Many children with learning disabilities show an inadequate ability and a poor grasp of sequence (Golick, 1970a, p. 9). The Wepman Committee likewise called attention to this disability area by stating that learning disabled children are often characterized by difficulties in "ordering the sounds and forms (referred to in para. 1 above) sequentially, both in sensory and motor acts" (Wepman et al., 1975).

Sequencing and memory functions are undoubtedly closely interrelated. Sequencing requires an efficient memory by which to order things, events or commands in a proper relationship. Irrespective of its independent or dependent status, the lack of ability to sequence is a fundamental characteristic of many children with learning disabilities, and is a significant hurdle to their school 
achievement and general adjustment (see also Gaddes \& Spellacy, 1977).

The interrelationship between memory and sequencing is illustrated most closely in the field of mathematics. The relationship between remembrance of the multiplication and the necessary steps to be taken in the process of multiplication or long division is obvious, but unfortunately too often overlooked by educators. This is an easy skill to evaluate in psychological or educational clinics. Sequencing is involved in almost everything the child is asked to do (i.e., dressing, starting an automobile, walking to and from school, making a sandwich). Children who have difficulty with sequencing skills usually have extreme problems in academic and social adjustment. Almost all learning involves sequencing - from learning to ride a bicycle and swimming to lacing shoes and buttoning shirts. These skills can easily be evaluated in the psychological clinic, but rarely are. Information regarding the child's abilities in these areas is essential in planning for the educational program in the school or clinic.

4. Figure-background relationship. Children with learning disabilities frequently have an inadequate ability to distinguish visual, auditory, and/or tactile figure-background relationship (Wepman et al., 1975; Frostig, Lefever, \& Wittelsey, 1961). This factor may also be related to attentiveness (to be discussed below) but in isolation it is in itself a serious processing impediment for learning. Undoubtedly the most extensive studies of this problem have been carried out with the cooperation of cerebral palsy children of the athetoid and spastic subtypes (Cruickshank et al., 1965). However, studies of the figurebackground pathology were completed by Werner and Strauss as early as 1941, and numerous other investigators have studied the phenomenon in relation to populations of children and youth with varying neurophysiological diagnoses. In practically every study that has examined the psychological characteristics of children with learning disabilities, the element of figure-ground pathology has been observed. Irrespective of its etiology, it is a serious impediment to appropriate development of reading skills, and its presence seriously impairs achievement in all forms of school-oriented learning situations. Strauss and Werner (Strauss and Lehtinen, 1947) initially developed a tachtistoscopic technique to evaluate figure and background differentiation skills in exogenous mentally retarded children. This was revised and refined by Cruickshank et al. (1965). Using $35 \mathrm{~mm}$ slides under time controlled situations and exposed for times varying from 1 second to $1 / 400$ th of a second, it was easy to evaluate the child's skill to select figure from background. The transposition of the child's abilities to the realities of reading, number concepts, writing and often to gross-motor figure-ground discrimination has proven valid and very helpful in developing an educational regimen for the child. In the original work of Strauss and Werner the authors published nine slides; in the work by Cruickshank et a1. (1965), sixteen slides involving three dimensional depictions were utilized.

5. Sensory integration. Children with learning disabilities have an inadequte capacity in "integrating intersensory information" (Birch \& Leford, 1964). Golick (1970a) stated that "some children seem to be able to handle tasks that are purely visual or tasks that are purely auditory, but seem to have difficulty in combining the information that comes to them through separate sense organs. For example, they may be able to see and recognize the letter a, and hear and repeat the vowe 1 sound, $\underline{a}$, but seem to be unable to learn to associate the two."

Frostig (1975) wrote of this aspect of processing deficits as "one of the most significant hurdles to learning and adjustment which faces the child with l'earning disabilities." 


\section{W. M. Cruickshank}

How often does the following situation occur in the classroom? "Listen, boys and girls," calls the teacher, "listen to me. Look at the blackboard. See what I have written there. Copy what you see on paper." "Listen" (auditory), "look" (visual), "copy" (motor) involve three neurological systems. For children who have difficulty in associating activities that involve two or more systems, a failure experience is certain to take place. Intersensory integration is another aspect of processing that demands research at all levels of child growth and development (see also Koupernik, MacKeith, \& Francis-Williams, 1975; Ayres, 1975).

Sensory integration has received less experimental investigation than most other aspects of perceptual processing in learning disabled children and youth. In the example noted in the preceeding paragraph the type of problem encountered daily by learning disabled children can easily be replicated by many others. The cautious reader will quickly note that intersensory organization involves memory, sequencing, and often auditory figure-ground differentiation in particular. The abilities or lack of abilities of the child in this type of situation can be qualitatively and subjectively evaluated situationally by the psychologist within the clinic facility. If more quantitative material is desired, particularly with young children, the subtest involving three or more commands found in the early forms of the Standford-Binet Intelligence Scale, or in other tests, may be utilized. I, however, have not found it necessary to rely on quantitative materials to obtain an understanding of the ability of the child in these relatively complex behaviors.

The examples used thus far are undoubtedly sufficient for the psychologist or the educational diagnostician to apply the qualitative approach to asessment to other processing issues inherent in the perceptual life of children with learning disabilities. Dissociation, for example, is one of these and lends itself to evaluation via the mechanisms of the Goldstein-Scheerer qualitative tests, the Vigotsky test (which also provides much information regarding cognitive abilities), and other similar materials.

Children with learning disabilities very often have an inadequate ability to associate. To state it negatively, these children are characterized by dissociation. Dissociation is the inability to see parts in relationship to the whole. These children have difficulty in conceptualizing new concepts that are built upon previously learned or recognized elements. Dissociation contributes to the problems in sequencing and to figure-ground pathology. On a functional basis these children have difficulty with pegboard designs, block designs, parquetry blocks, lacing shoes, as well as with more abstract wholes that must be developed from related parts (see Strauss \& Lehtinen, 1947; Cruickshank, 1977). The individual parts appear to have greater significance for the child than does the ultimate whole concept, probably because the parts contain many more stimuli. The report of the Australian Select Committee on Specific Learning Disabilities (1976, p. 129) refers to dissociation as a deficiency in "part-whole synthesis and analysis." This phenomenon, as with figure-background disturbance, and probably some of the other characteristics mentioned earlier, is closely related to the attention problems that these children often demonstrate.

Other processing skills, or deficiencies in processing, which must be carefully evaluated by psychologists, include a wide variety of developmental abilities. Each of the following needs careful attention whether it be via quantitative or qualitative means. I personally prefer the latter and am of the opinion that experience and knowledge of children and their perceptual development provides excellent bases for understanding the capacities of learning disabled children and minimizing the deficiences of objective tests when these are 
applied to children with varying degrees and patterns of sensory processing deficits. Among those developmental elements that must be assessed are the issues of perseveration, rate of perceptual processing, time and space orientation (directionality skills), concepts of closure, perceptual motor functions, language and communications, and the exceedingly complicated problems related to attention deficits, which in particular deserves further consideration.

Children with learning disabilities are often characterized by attention disturbances (Cruickshank, 1977; Strauss and Lehtinen, 1947; and many others). Hagan and Keil (1975) and Lewis (1975) have made excellent analyses of the of the problems of attention and attention disturbances in children with learning disabilities. At least one point of view holds that the attention disturbances of the learning disabilities child are the result of being unable to refrain from reacting to extraneous environmental stimuli, which may include those of a visual, auditory, tactual or other modality. The extraneous stimuli may be internal as well as external to the organism (Rappaport, 1969). Kinesthetic stimuli resulting from clothing that bind (tactual stimuli) may be the source of real, but unconscious disturbances for the child. Extraneous stimuli may be of two major types: sensory or motor. Whereas the neurologically intact normal child or youth can negatively adapt to the unessential, the unusual or the extraneous, the child with perceptual processing deficits at times appears almost driven to respond to them. In a classic paper, Goldstein and Scheerer speak of this characteristic in terms of "drivenness" (1941). Strauss and Werner (1941) (in Strauss and Lehtinen, 1947) and Cruickshank (1977) have referred to this behavior as forced responsiveness to stimuli.

If the child is driven to respond to stimuli of whatseover nature, the attention span will be significantly shortened (Kronick, 1973, p. 143). A short attention span is directly related to the amount of time the child has to learn. It is not unusual to see children in a clinical situation where the attention span is of two or three minutes duration, and children with attention spans as short as fifteen to thirty seconds have been observed on many occasions. But even longer attention spans, yet short by normal standards, will produce learning and adjustment problems for the child in school or home learning situations.

Al though little if any quantitative data is available, clinicians often report that these children make deviant or unusual responses to reinforcement. The etiology of this observed behavior is not clear, but it is possible that this also is directly related to a short attention span or to attention disturbances of other natures. Likewise, these children may process stimuli at a different rate than normal children. If left alone these children are observed to have an erratic rate of processing, slower rates, or sometimes appear to be so overwhelmed by the task of processing that they function behaviorally on almost totally a trial-and-error basis.

Previously it was stated that the lack of attention or forced responsivenes to stimuli is probably related to dissociation and to figure-ground disturbance, among other characteristics (e.g., closure). The backgrounds of most visual situations and of many auditory and tactual representations contain much more stimuli than does the figure itself. Cruickshank et al. (1965) have shown that it takes a relatively large increase in the value of a figure (through size, color, and commonness of concept) before a child with visual perceptual processing deficits can perceive it adequately on a routine basis. Grube (1978) has demonstrated that this capacity is developmental in normal children (at least during the chronological years of four through seven). The neurologically handicapped subjects in the Cruickshank et al. (1975) study were between the ages of six and sixteen years. 
The normal auditory climate of a classroom, home, or playground contains a great amount of stimuli. The visual environment of a printed page in a child's reading or arithmetic book contains hundreds, if not thousands of background stimuli in comparison to the few stimuli contained in the specific word or set of numerals that the child is attempting to respond to at a particular moment. Learning disabilities children are often characterized as having poor table manners. This may in part be due to the excessive number of background stimuli (many of which are motoric in nature) surrounding the child at mealtime in comparison to the specific piece of food being put by him or her onto a fork or spoon. The psychologist often sees this characteristic of overreaction to stimuli defeating the child when the larter is asked to perform on marble boards, Rorschach cards, or other types of psychological testing material.

These comments are written by way of stating that the factor of stimuli attraction (a) reduces the child's attention span, and (b) may well be a significant deterrent to appropriate processing in other related areas (i.e., increasing chances of dissocation, hindering closure, producing figure-background confusions and, among other things, interfering with the capacity to make fine discriminations (par. 1 above), which are so much a part of good initial reading and speaking).

There is an interesting vicious circle that is often observed in the case of attention disturbances. It is not a part of processing deficits per se, but certainly serves to increase the concept of failure in the learning disabilities child. Attraction to stimuli reduces the attention span. The reduced attention span produces the chances of failure experiences. Continued failure experiences may further reduce the length of the attention span, and may tend to drive the child to trial-and-error responses to environmental stimuli. In some children with severe manifestations of learning disabilities this cyclical behavior produces extraordinary adjustment problems for the child, his parents, teachers, and others who must cope with the behaior on a day-to-day basis.

\section{THE NEEDS OF THE CHILD}

Al1 children need success, but for hyperactive children the need is even more basic since they have had so many failures in the past. Most children have found ways of achieving recognition for their endeavors. Because parents have success experiences through their children's successes, parents tend to set more situations in which the child can prove himself. When the child does succeed, a strong parent-child relationship is formed. The hyperactive child, however, does not have this built-in insurance.

\section{EDUCATIONAL IMPLICATIONS}

The close and intimate relationship between psychological diagnosis and educational programming should be evident. Within reasonable limitations, each characteristic of psychopathology and perceptual processing deficits should and can be matched with an educational technique or educational adjustment. The degree to which this can be carried out will, in fact, in large measure determine the degree to which the educational regimen will be effective.

Because the issue is a complicated one, the implications for education will be only briefly discussed. Some essentials to be kept in mind in a teacher-child relationship or parent-child relationship will be mentioned.

1. A level of achievement at which the child has already experienced 
success must be established. The concept of remedial education is one which educators are prone to misrepresent. Remediation implies that something already learned, if modified, will result in achievement for the individual. With regards to the hyperactive child, new learning is required, initial concepts must be established. The remedial reading teacher is not the one to handle this type of child's problems. The teacher must be equipped with the skills to begin where the child is currently functioning.

2. The educational program must be geared to the psychopathology of the child. It is obvious that the typical reading lesson is inappropriate for the child with figure-ground problems. In many ways it is the exact opposite of what he needs. Figuare-ground problems must be reduced to a mimimum for such a child. Thus, the reading material for this child may use many pages of paper with only one word at a time per page. With this kind of arrangement there are no background stimuli to reverse with the foreground figure. There is only one figure per page. Instead of numerous arithmetic problems crowded on a single page, it is recommended that only one problem appear on the page. As the child advances it is possible to gradually increase the number of words or problems per page.

3. A time span optimal for conditioning to take place must always be an integral part of the educational program. If a child responds to inessential stimuli, these stimuli must be reduced in the learning environment. The bright and multicolored classroom, the best one for most children, is the worst classroom for the hyperactive child. Great care must be taken to reduce extraneous stimulation. Walls, furniture, woodwork and floor covering should all be the same color. Windows should have opaque glass and the entire room should be sound-treated. Cubicles where the child may work stimulus-free are also of great value.

4. The child should be within arm's reach of the teacher during teaching. Although not always possible, it is essential that a close personal relationship be established between the child and adult. The tendency to dissociate and reverse the field causes the hyperactive child to have a very confused understanding of what the adult is physically. The child may very well perceive the adult in the same confused manner that he perceives numerals, letters, or other symbols. Such difficulties in perception easily result in the formation of an insecure relationship between the child and the objects and people in his environment. Being within arm's reach of the teacher and occasionally feeling the teacher's arm on his shoulder during instruction, the child is reassured of his physical surroundings and his placement in that environment.

5. Finally, the child's program must be structured environmentally and methodologically. Just as environmental structure through stimuli reduction and the cubicle are necessary, everything taking place in the classroom must also be structured. Permissiveness is definitely not needed here. Success experiences, something the hyperactive child is not likely to have had, are necessary before he can be expected to make adequate choices. In finding the basic level to begin teaching the child, the teacher is seeking a base upon which to provide an adequate conditioning experience. Once success experiences are rewarded and developed, security in learning will result. After confidence building, choices can then be provided with an escape valve in order that he feels comfortable in retreating again to a level of performance where he feels assured that he can succeed. This aspect must be understood if the child is to attempt something new and to move from one behavioral plateau to another.

In conclusion, it should be emphasized that it is essential that extensive psychological and behavioral information be available about the hyperactive 
child in order that the teaching method and materials can be structured to fit the needs of the individual child. The educational material, technique, and setting for the hyperactive child must reflect a direct correlation with the psychological make-up of the child. Only by doing this will we truly attempt to meet the needs of the hyperactive child.

\section{REFERENCES}

AUSTRALIAN SELECT COMMITTEE ON SPECIFIC LEARNING DISABILITIES (1976). Learning difficulties in children and adults. Canberra: Australian Government Publishing Service.

AYRES, A.J. (1975). Sensorimotor foundations of academic ability. In W. M. Cruickshank \& D. P. Hallahan (Eds.), Perceptual and learning disabilities in children (Vol . 2). Syracuse: Syracuse University Press

BIRCH, H.G. , \& LEFORD, A. (1964). Two strategies for studying perception in "b rain-damaged" children. In H.G. Birch (Ed.), Brain damage in children (pp. 46-60). Baltimore: Williams and Wilkins.

CRUICKSHANK, W.M. (1977 [1966]). The brain injured child in home, school and community. Revised as Learning disabilities in home, school and community. Syracuse: Syracuse University Press.

CRUICKSHANK, W.M. (1981). Le arning disabilities: A definitional statement," from W.M. Cruickshank, Selected Writings (Vol. 2, Chap. 6, pp. 80-110). Syracuse: Syracuse University Press.

CRUICKSHANK, W.M., BICE, H. V. , WALLEN, H. E. \& \& LYNCH, K.S. (1965). Perception and cerebral palsy (Revised ed.). Syracuse: Syracuse University Press.

CRUICKSHANK, W.M., BENTZEN, F., RATZERG, F., \& TANNHAUSER, M. (1961). A teaching method for brain-injured and hyperactive children. Syracuse: Syracuse University Press

FROSTIG, M. (1975). The role of perception in the integration of psychological functions. In W.M. Cruickshank \& D. P. Hallahan (Eds.), Perceptual and learning disabilities in children, Vol. 1. Syracuse: Syracuse University Press.

FROSTIG, M., LEFEVER, D.W., \& WITTELSEY, R.B. (1981). A developmental test of visual perception for evaluating normal and neurologically handicapped children. Perceptual Motor Skills, 383-394

GADDES, W.H. , \& SPELLACY, F.J. (1977). Serial order perception and motor performance in children and their relation to academic achievement. victoria, $\bar{B} . \mathrm{C}$. , Department of Psychology, University of Victoria, Research Monograph 31.

GOLDSTEIN, K., \& SCHEERER, M. (1941). Abstract and concrete behavior: An experimental study in special tests. Psychological Monographs, 53, 1-151.

GOLICK, M. (1970a). A parent's guide to learning problems. Montrea1: Quebec Association for Children with Learning Disabilities.

GOLICK, M. (1970b). She thought I was dumb but I told her I had a learning disability. Toronto: The Pryant Press.

GRUBE, M.M. (1978). Un published doctoral dissertation, University of Michigan, Rackham School of Graduate Studies.

HAGAN, J., \& KAIL, R.V. (1975). The role of attention in perceptual and cognitive development. In W.M. Cruickshank, and D.P. Hallahan (Eds.), Perceptual and learning disabilities in children (Vo1. 2, p. 165). Syracuse: Syracuse University Press.

KOUPERNIK, C. , MACKEITH, R., \& FRANCIS-WILLIAMS, J. (1975). Neurological correlates of motor and perceptual development. In W.M. Cruickshank, \& D.P. Hallahan (Eds.), Perceptual and learning disabilities in children (Vol. 2). Syracuse: Syracuse University Press.

KRONICK, D. (1973). A word or two about learning disabilities. San Rafael, CA: Academic Therapy Publications. 
LEWIS, M. (1975). The development of attention and perception in the infant and young child. In W.M. Cruickshank \& D.P. Hallahan (Eds.), Perception and learning disabilities in children (Vol. 2). Syracuse: Syracuse University Press.

RAPPAPORT, S. (1969). Education for children with brain dysfunction. Syracuse: Syracuse University Press.

STOTT, D.H. (1972). The parent as a teacher. Toronto: New Press.

STRAUSS, A., \& LEHTINEN, L. (1947). The psychopathology and education of the brain injured child. New York: Grune and Stratton.

WE PMAN, J.M. (1975). Auditory perception and imperception. In W.M. Cruickshank, \& D.P. Hallahan (Eds.), Perceptual and learning disabilities in children (Vol. 2). (yracuse: Syracuse University Press.

WEPM AN, J.M., CRUICKSHANK, W.M., STROTHER, C. \& DEUTSCH, C. (1975) . Le arning disabilities. In N. Hobbs (Ed.), Issues in classification of children (Vol. 1). San Francisco: Jossey-Bass Publishers.

THE AUTHOR

WILIIAM M. CRUICKSHANK is a Professor at the Child and Family Health Program in the School of Public Health, The University of Michigan. 